\title{
Investigation of Antimony in Natural Water and Leaching from Polyethylene Terephthalate (PET) Bottled Water
}

\author{
Mihyun Jo, Taeyuel Kim, Sirim Choi, Jongpil Jung, Hee-il Song, Hyunjin Lee, Gyoungsu Park, Samhwa \\ Lim, Yeonkook Sung, Jogyo Oh \\ Gyeonggi Province Institute of Health and Environment \\ 1 Cheongsa-ro, Uijeongbu-si, Gyeonggi-do, Republic of Korea \\ jomh@gg.go.kr
}

\begin{abstract}
Antimony (Sb) is one of the trace hazardous compounds in drinking water. Recent studies demonstrated that polyethylene terephthalate (PET) bottles can release antimony into water. It is also found on natural environment such as groundwater and crustal rocks. The natural content of $\mathrm{Sb}$ in northern Gyeonggi province in South Korea was very low range from 0.02 0.32 $\mu \mathrm{g} / \mathrm{L}$. The source water and tap water for 15 water supply plants from river or reservoir showed $0.13 \mu \mathrm{g} / \mathrm{L}$ on average. The groundwater concentration from 50 mineral springs indicated significantly low at $0.02 \mu \mathrm{g} / \mathrm{L}$. The concentration of antimony was investigated in 47 bottled water brands on market. The average of Sb in bottled water brands was $0.57 \mu \mathrm{g} / \mathrm{L}$. The detection rate was $100 \%$ in these products. Otherwise, raw water for bottled water contained $0.32 \mu \mathrm{g} / \mathrm{L}$ of antimony and detection rate was $90.7 \%$. As a results of leaching experiment, antimony content in PET bottled water was increased from 1.04 to $9.84 \mu \mathrm{g} / \mathrm{L}$ under $60^{\circ} \mathrm{C}$ after 12 weeks. In case, the bottled water was stored in over $35^{\circ} \mathrm{C}$, antimony leached into water. UV-ray irradiation to bottled water not induced increasing antimony release into water following 14days.
\end{abstract}

Keywords: Antimony, Polyethylene Terephthalate(PET), Leaching, Drinking Water

\section{Introduction}

Antimony is one of the trace hazardous components in drinking water. Polyethylene terephthalate(PET) widely used to container for bottled water. Antimony trioxide $\left(\mathrm{Sb}_{2} \mathrm{O}_{3}\right)$ is one of the most important catalysts widely used for solid-phased poly condensation of PET. It offers high catalytic activity, does not induce undesirable color, and has a low tendency to catalyse side reactions[1]. Polyethylene terephthalate(PET) has wide acceptance for use in direct contact with food, can be recycled and can be depolymerized to its monomer constituents[2]. In a recent study of Sb in bottled water in Europe and Canada, it was shown that the water become contaminated during storage because of Sb leaching from PET[3]. The bottled water market is continuously growing amount up from 2.1 million ton of 2004 to 3.5 million ton of 2013 in South Korea[4]. Recommended standard for tap water have regulated $20 \mu \mathrm{g} / \mathrm{L}$ of antimony since 1998 in Korea. Recently, recommended standard for bottled water regulated in 2014 that should be inspected within $15 \mu \mathrm{g} / \mathrm{L}$. Europe Union, World Health Organization, United States and Japan also have drinking water standards for antimony at $5 \mu \mathrm{g} / \mathrm{L}, 20 \mu \mathrm{g} / \mathrm{L}, 6 \mu \mathrm{g} / \mathrm{L}$ and 2 $\mu \mathrm{g} / \mathrm{L}$, respectively. Bottles made using PET typically contain 100 300 of $\mathrm{mg} / \mathrm{kg} \mathrm{Sb}$ in the plastic. In contrast to bottles, antimony is found at natural environment from rocks, groundwater and river. Concentrations of $\mathrm{Sb}$ in crustal rocks is about $0.3 \mathrm{mg} / \mathrm{kg}$ and pristine groundwater and surface water normally range from 0.1 to $0.2 \mu \mathrm{g} / \mathrm{L}[5]$. The International Agency for Research on Cancer(IARC) was classified as possibly carcinogenic to humans; Group 2B. It can cause nausea, vomiting and diarrhea when exposed MCL in short periods. The exposure of long term elevated Sb can lead to increased blood cholesterol and decreased blood sugar[6].

The objective of this study was to investigate antimony concentration in drinking water such as source and tap water, natural springs, raw water for bottled water and products on market and then compare the antimony content in natural environment and PET bottled water. In addition, the effects of storage duration, temperature and ultraviolet(UV) on leaching of $\mathrm{Sb}$ from PET bottle into water were examined. 


\section{Material and methods}

\subsection{Sb concentration in drinking water}

Antimony content was investigated in source water from river or reservoir and tap water in 15 of water supply plants, 50 of mineral springs located in northern Gyeonggi province in Korea. The source water sampled from 54 of intake holes in 13 of manufacturer plants. To investigate the antimony leaching effect into water of PET bottles, 47 commercial brands of PET bottled water were collected in market include domestic manufactured one and imported products. All samples were analysed by inductively coupled plasma-mass(Bruker aurora, Germany).

\subsection{Leaching experiment in PET bottled water}

PET bottled water stored in $4,21,35,45$ and $60^{\circ} \mathrm{C}$ for 12 weeks. Sb concentration was analysed for every 2 weeks during that period. Polypropylene (PP) and glass bottles were used for control sample to compare to leaching amount of antimony from PET bottles. PET bottled water stored for 2, 6, 12, 24, 36, 48hrs, 3, 7, 9, 12, 14days under ultraviolet(UV)ray. Also, antimony concentration for 47 brands of bottled water was again analysed after six months under room temperature and natural sunlight.

\section{Results \& Discussion}

\subsection{Natural Sb concentration for source and tap water in water supply plants and mineral springs}

Natural antimony content in source water from river or reservoir to make tap water in fifteen water supply plants was $0.13 \mu \mathrm{g} / \mathrm{L}$ of average. The average of tap water also indicated same value with source water. Although concentration was very low to not enough to compare variation, treatment process did not influence antimony concentration. In Korea, the recommended standard of antimony content for tap water is $20 \mu \mathrm{g} / \mathrm{L}$. The average of tap water in northern Gyeonggi area was $0.65 \%$ compared to that standard value. The average level of the drinking water public facilities which use the groundwater as mineral springs for each of ten sites in five cities in Gyeonggi province was $0.02 \mu \mathrm{g} / \mathrm{L}$ that were approximately $1 / 10$ times lower than source water from river drift or lake water.

\subsection{Comparison of Sb concentration with raw water for bottled water and PET bottled water}

As a result of analysing the raw water for bottled water from 54 intake holes visited 13 manufacturers of drinking water, the antimony detection rate was $90.7 \%$ and the average value was $0.32 \mu \mathrm{g} / \mathrm{L}$. The maximum value was $1.64 \mu \mathrm{g} / \mathrm{L}$ and the minimum was not detected. The average for antimony concentration of bottled waters which were produced on that day when the samples got into our laboratory indicated $0.44 \mu \mathrm{g} / \mathrm{L}$. It was high than natural antimony concentration of raw water. To investigate the antimony leaching effect from PET bottles into water during sales to customer, we purchased 47 brands of products and analysed the antimony contents. As a result, the detection rate was $100 \%$ for these bottled waters, the antimony average of domestic products was $0.75 \mu \mathrm{g} / \mathrm{L}$, the imported products showed $0.55 \mu \mathrm{g} / \mathrm{L}$, the deep sea water was $0.41 \mu \mathrm{g} / \mathrm{L}$ and the total average value indicated $0.57 \mu \mathrm{g} / \mathrm{L}$. The bottled water recommended standard of antimony is 15 $\mu \mathrm{g} / \mathrm{L}$ in Korea, which was $3.8 \%$ of the standard. The antimony concentration of bottled water we purchased in the market was higher than first day products manufactured in plant at $0.44 \mu \mathrm{g} / \mathrm{L}$, indicating that antimony leaching was caused on storage.

\subsection{Effects of storage duration, temperature and UV-ray on Sb leaching from PET bottle}

Antimony content analysed at 2 weeks intervals for 12 weeks showed rarely change concentration under 4 and $21^{\circ} \mathrm{C}$. Otherwise the antimony concentration increased 1.6 times from 1.60 to $2.50 \mu \mathrm{g} / \mathrm{L}$ at $35^{\circ} \mathrm{C}$ following 12 weeks and 2.1 times increased from 1.71 to $3.60 \mu \mathrm{g} / \mathrm{L}$ at $45^{\circ} \mathrm{C}$. Finally, antimony increased about 9.8 times from 1.04 to $9.84 \mu \mathrm{g} / \mathrm{L}$ at $60^{\circ} \mathrm{C}$. At $60^{\circ} \mathrm{C}$ of storage condition, it showed rapid increase after 2 weeks, but did not show any significant change until 8 weeks, but started to increase again after 10 weeks and showed $9.84 \mu \mathrm{g} / \mathrm{L}$ after 12 weeks. However, in case of PP and glass materials of bottles did not any change to antimony concentration. As a result of leaching experiment with UV-ray irradiation, antimony increased from 0.02 to $0.19 \mu \mathrm{g} / \mathrm{L}$ was observed after 12 hours of UV irradiation. After 24, 48 hours, 3, $7,9,12$, and 14 days no increase was observed any more. 


\subsection{Natural Degradation of PET bottled water under ambient condition}

The antimony content of antimony was increased from 0.47 to $0.63 \mu \mathrm{g} / \mathrm{L}$ for domestic bottled water, 0.55 to $0.83 \mu \mathrm{g} / \mathrm{L}$ for imported ones and deep seawater bottles increased from 0.41 to $0.79 \mu \mathrm{g} / \mathrm{L}$ under ambient temperature and let them exposure of natural sunlight after six month. On average, 37 brands of bottled water increased to $0.27 \mu \mathrm{g} / \mathrm{L}$ during that time. it was also found that it increased in the safe level under daily condition within the domestic recommended standard.

\section{Conclusion}

In the northern area of Gyeonggi province of Korea, natural concentration of antimony indicated that raw water for bottled water was $0.32 \mu \mathrm{g} / \mathrm{L}$. Source water from river or reservoir was $0.13 \mu \mathrm{g} / \mathrm{L}$ and then mineral springs for public facilities showed $0.02 \mu \mathrm{g} / \mathrm{L}$. For PET bottled water brands, the average value was $0.57 \mu \mathrm{g} / \mathrm{L}$ and detection rate was $100 \%$. Otherwise detection rate of raw water to bottled water showed $90.7 \%$. As a results of leaching experiment for PET bottled water, leaching amount was rapidly increased till $9.84 \mu \mathrm{g} / \mathrm{L}$ after 12 weeks in $60^{\circ} \mathrm{C}$, though, it was less than recommended standard in Korea. And UV-ray irradiation to bottled water for 14days induced increasing antimony release into water very slightly.

\section{References}

[1] B. Duh, "Effect of antimony catalyst on solid-state polycondensation of poly(ethylene terephthalate)," Polymer, vol. 43, pp. 3147-3154, 2002.

[2] W. A. MacDonald, "New advances in polyethylene terephthalate polymerization and degradation," Polym Int., vol. 51, pp. 923-930, 2002.

[3] W. Shotyk, M. Krachler and B. Chen, "Contamination of canadian and european bottled waters with antimony leaching from PET containers," J. Environ Monitor., vol. 8, pp. 288-292, 2006.

[4] M. Environment, "Environmental statistics yearbook," R. K., pp.125, 2015.

[5] H. J. M. Bowen, Environmental chemistry of the elements. London, Academic press, 1979.

[6] P. Westerhoff, P. Prapaipong and A. Hillaireau, "Antimony leaching from polyethylene terephthalate (PET) plastic used for bottled drinking water," J. Water Res., vol. 42, pp. 551-556, 2008. 